\title{
Why sex selection should be legal
}

David McCarthy University of Bristol

\begin{abstract}
Reliable medically assisted sex selection which does not involve abortion or infanticide has recently become available, and has been used for non-medical reasons. This raises questions about the morality of sex selection for non-medical reasons. But reasonable people continue to disagree about the answers to these questions. So another set of questions is about what the law should be on medically assisted sex selection for non-medical reasons in the face of reasonable disagreement about the morality of sex selection. This paper sketches a way of thinking about what the law should be, and concludes, contrary to what the law is in many places, that medically assisted sex selection for non-medical reasons ought to be legal.

(Fournal of Medical Ethics 2001;27:302-307)
\end{abstract}

Keywords: Sex selection; law; morality; liberalism; abortion; non-identity problem

It is now possible, with reasonable reliability, to select the sex of one's child. There are many ways of doing this with medical assistance. One way is by terminating pregnancy if the fetus is not the desired sex. But recent attention has focused on two methods. One is the preconceptual method of separating $\mathrm{X}$ and $\mathrm{Y}$ sperm. This technique increases the chances of a couple getting a girl if that is the sex they are trying to get from about $50 \%$ to $85 \%$, and increases the chances of their getting a boy if that is the sex they are trying to get from about $50 \%$ to $65 \%$. $^{1}$ The other is the postconceptual method of in vitro fertilisation and preimplantation genetic diagnosis. ${ }^{2}$ This is the only method which offers a good chance of a pregnancy with a fetus of the chosen sex and a near zero chance of a pregnancy with a fetus of the non-chosen sex. Since preimplantation genetic diagnosis has only recently become available, it is only recently that a reliable method of sex selection which does not involve termination of pregnancy has become available.

Discussions of sex selection suggest that the central issue to be resolved is the morality of sex selection. No doubt any couple at least considering sex selection will want to have a position on this. But there is another issue. Compare the abortion debate. $^{3}$ Reasonable people take different sides on the moral status of the fetus, on when the pregnant woman's interests outweigh the interests of the fetus, and so on. In a pluralistic liberal democratic society, this generates a further question: what should the law on abortion be in the face of reasonable disagreement about the morality of abortion? And one's position on the morality of abortion need not coincide with one's position on what the law should be. For example, many people believe that abortion is wrong, and would not choose to have one themselves, but also believe that women should have the liberty to decide for themselves whether to have an abortion. Thus the other issue in the debate about sex selection is: what should the law be on sex selection in the face of disagreement among reasonable people about the morality of sex selection?

We might try to resolve this by seeking unanimity on the morality. But if the abortion debate is any indication, that is unlikely to happen soon. In the present and perhaps permanent state of disagreement among reasonable people about the morality of sex selection, we need a different way of asking what the law should be. At present, medically assisted sex selection for non-medical reasons is illegal in the United Kingdom, Canada, ${ }^{4}$ and in two states in Australia. ${ }^{2}$ This paper outlines a way of thinking about what the law should be, and concludes that sex selection ought to be legal.

\section{Liberty and the law}

An ongoing, and perhaps permanent, feature of free societies is that reasonable people disagree on basic values. In such conditions, there are really only two choices. One is to have a society in which whichever interest group happens to achieve the balance of power gets to force its values on others who can reasonably disagree with those values. The other is to have a society in which value disputes are resolved in a way in which no one can reasonably reject. ${ }^{5}$ I will assume that the second choice is correct (and possible), but will not try to argue for this in any extended way. My question is what the law on sex selection should be in such a society .

Given that there are disputes over a number of basic values, the usual method of trying to resolve them in a way no one could reasonably reject is to try to appeal to agreement on more general value questions. ${ }^{7}$ Thus there is dispute over which religions, if any, merit our support, and dispute over which forms of expression are worth making. But we can agree that freedom of thought and freedom of expression are valuable, and that restrictions on them need substantial justification, even though we continue to disagree on the ways in which these freedoms should be exercised. More generally, we can agree on the value of quite broad liberties even though we disagree on the value of particular ways of exercising them.

In some ways, this is a compromise. We do not want others imposing their values on us, and so we 
are prepared not to impose our values on them in exchange. Thus in assessing the consequences of proposed laws or public policies, we are prepared to use a conception of benefits and burdens which others cannot reasonably reject: for example, we are prepared to regard restrictions on freedom of thought or expression as a significant burden independently of the content of the restriction. But it is more than a compromise. It reflects a recognition of the fact that people are free and equal: free in the sense that people are able to make their own decisions about the merits of various different ways of living, and equal in the sense that being free in that way is the basis for their political standing. ${ }^{8}$ Again, compare abortion. Having control over such major aspects of their lives (and their bodies) as when and whether to have children is seen by many as fundamental to women's achieving full political equality. Assessing benefits and burdens in terms no one could reasonably reject therefore reflects a commitment to a fundamental political ideal of a society of people who are regarded as free and equal. ${ }^{6}$

\section{An exacting requirement}

While this provides a general presumption in favour of various broad liberties, the commitment to liberty is never absolute. A commitment to freedom of expression, for example, does not require that we do not penalise someone who shouts "Fire!" as a hoax in a crowded cinema. More generally, a commitment to freedom of expression can acknowledge that there can be restrictions on time and place of expression. Nevertheless, the commitment to liberty is basic: if society significantly restricts the liberty of some, it needs to be on grounds that those restrained could not reasonably reject.

Now to sex selection. Some people want to be able to select the sex of their children. And the decision to do this is not to be taken lightly. The only reliable way of selecting sex which does not require abortion or infanticide, in vitro fertilisation plus preimplantation genetic diagnosis, is highly invasive, and the fact that some women are prepared to go through with it tells us that, for one reason or another, it is very important to them. The question, then, is whether any justification for restricting their liberty to select the sex of their children can be made on grounds they cannot reasonably reject. On the other hand, as the discussion of freedom of expression shows, the commitment to liberty does not rule out the possibility that such grounds could be put forward.

In order to resolve this kind of issue, we need to find some way of characterising the liberty in question, its value, and the kinds of interests that restricting the liberty might protect or promote, all in terms no one can reasonably reject. This is an exacting requirement. Someone might, on religious grounds, believe that sex selection is wrong, or might believe that it is wrong to interfere with natural processes. But even if it reasonable to accept such grounds, it is also reasonable to reject them: it is reasonable to reject all religions and it is reasonable to believe that there is nothing morally privileged about natural processes.

In order to settle what would justify restricting people' s liberty to select the sex of their children, we need a way of characterising the liberty at a level at which we can agree on its value. Many people claim that it makes no important difference what the sex of their children is. Some disagree, as witnessed by the efforts they are prepared to go through to select the sex of their child. Evidence suggests that by far the most common reason in prosperous pluralistic liberal democracies is that couples want to have a balanced family. ${ }^{19} 10$ For example, they have had two boys, and want to have only one more child, but believe that their family life will be richer and better balanced if the third child they have is a girl. One might not agree with this, but it is clearly not a flat-out unreasonable belief either. (Compare the fact that many people who reproduce normally hope to have a child of a particular sex, and are disappointed to get a child of the opposite sex; few people find this an unreasonable attitude.) Thus there is significant and reasonable disagreement over the value of the liberty to select the sex of one's children. This means that to characterise the liberty at a level on which we can agree on its value, we need to characterise it more generally. The natural proposal is that what is in question is the liberty to make one's own reproductive choices. This covers the liberty to select the sex of one's children, but it also covers such things as the liberty to decide how many children to have, when to have them, and whether to have any at all. One cannot reasonably reject the claim that this liberty has great value.

\section{Sharp disagreement}

It is perhaps worth noting that there is sharp disagreement over the most appropriate ways to exercise this liberty independently of sex selection. Some people believe that people who choose not to have children are behaving wrongly; others disagree. Some people believe that careful use of contraception to have children at times which will best fit in with the parents' careers is also wrong; others disagree. Some people believe that it is irresponsible to have more than two or three children; others disagree. Some people believe that it is wrong to have children outside marriage; others disagree. Some people believe it is acceptable to terminate a pregnancy with Down's syndrome or cleft lip; others disagree. And so on. Nevertheless, we have come to regard a wide range of such choices as reasonable, even if we would not make them ourselves, and to regard the liberty to make one's own reproductive choices as a basic liberty despite the fact that we continue to disagree over the merits of particular ways of exercising that liberty. In this respect, the liberty to make one' s own reproductive choices is no different from the liberties associated with freedom of thought or freedom of expression. 
What grounds would be weighty enough to oppose this liberty? It is important to note that since it is the liberty to make one's own reproductive choices that is at issue, this question is not specifically about sex selection: compare the idea that the grounds that are weighty enough to oppose freedom of expression need to be independent of an evaluation of the merits of a particular form of expression. The grounds on which the reproductive liberty can be opposed should in principle apply to restrictions of that liberty apart from restrictions on selecting sex. Three broad sorts of grounds seem reasonable. First, particular ways of making reproductive decisions may interfere with the basic liberties of others: no one would take seriously the idea that my reproductive liberties extend to having children with a woman who does not consent. Second, particular ways of making reproductive decisions may be associated with harm, or the risk of harm. Third, the legality of particular ways of making reproductive decisions may be associated with broader social costs.

It is hard to see that selecting sex is interfering with the basic liberties of others. Our question then becomes whether selecting sex is associated with significant harms or social costs, but it is always a useful consistency check to see whether we think that such supposed harms or social costs are sufficient to oppose other kinds of reproductive decisions.

\section{Harm}

The main worries about harm are harm to the child and harm to the mother. In vitro fertilisation is associated with morbidity, but so is pregnancy, and the appropriate response is to make the mother well informed about the risks and make sure she is not being coerced into the choice. Of more concern is harm to the child.

Suppose that there is a significant risk that the process of sex selection will result in a child with a disease or disability. For this to result in an objection to sex selection, we need to assume that the risk is significantly greater than the far from trivial risk in normal pregnancy. If the risk is significantly greater, many people would regard this as a reason not to sex select. This, however, is more complex than it appears: unlike other reproductive behaviours which are associated with harm to the future child, such as smoking during pregnancy, sex selection is almost certainly identity affecting. Suppose that a child is born as the result of medically assisted sex selection and has a disease or disability which was caused by the process of sex selection but nevertheless has a life worth living. Had that process not been used, the child would almost certainly not have come into existence at all. It would have been almost certain that either another sperm would have fertilised the egg or the egg would not have been fertilised at all. In either case, the child would not exist. It is therefore implausible that the child has a complaint since it has a life worth living and had sex selection not been used, it would not have existed at all.
However, consider a case discussed by Parfit. ${ }^{11} \mathrm{~A}$ woman can conceive now, in which case the child would have a serious disease, but still have a life worth living, or she can wait two months to conceive, and have a different child with no disease. Many people claim that, in this case, it would be wrong for the woman not to wait. However, we cannot plausibly claim that if the woman does not wait then someone will have been harmed since her child, although diseased, will have a life worth living and the alternative was non-existence. If we claim that it would be wrong for the woman to wait, we need to accept, in a slogan, that there can be wrongdoing without harm. ${ }^{11}$ For example, we might accept this principle: if we have a choice of which of two people to make exist, and the first would be significantly worse off than the second, then (other things being equal) it would be morally wrong to make the first exist even when the first would have a life worth living. ${ }^{12}$ Since this principle accepts that there can be moral wrongdoing without harm, Parfit calls it a non person affecting principle.

Suppose that smoking during pregnancy leads to significant morbidity in $10 \%$ of pregnancies, and that sex selection also leads to significant morbidity in $10 \%$ of cases. The strongest remotely plausible non person affecting principle will then say that there is no moral difference between smoking during pregnancy and selecting sex. If such a principle could not be reasonably rejected, there would be grounds for the law treating smoking during pregnancy and selecting sex in the same way. But many moral philosophers believe that such a strong non person affecting principles is false. It therefore seems plausible that, at the very least, such a strong non person affecting principle is reasonably rejectable. But that means that women should have more liberty in non person affecting cases than in person affecting cases. On the assumption that the hypothetical figures are correct, that would entail that the law ought to take a dimmer view of smoking during pregnancy than of sex selection.

A different issue connected with harm is resource allocation. If health care is publicly funded, and if sex selection were sufficiently risky, we might refuse to allow it on the grounds of the cost to the health care system of dealing with future sick children and adults even if the procedure itself were privately funded. But it is also worth bearing in mind that there are many activities which impose costs on the health care system which we do not prohibit, so it appears that we typically attach significant weight to liberty and are vulnerable to the charge of inconsistency if we prohibit some activities rather than others without further reasons.

In summary, if sex selection results in significant morbidity, the case for making it illegal is far from overwhelming. But these points are most likely moot. Although the long term methods of some methods (preimplantation genetic diagnosis, intracytoplasmic sperm injection, ${ }^{13}$ cryopreservation $^{14}{ }^{15}$ ) of sex selection are still not known for certain, there is good, if not conclusive, evidence that the risks are not significant. ${ }^{16}$ But this means that considerations 
of harm to the child, or anyone else for that matter, do not provide grounds for making sex selection illegal.

\section{Social costs}

By "social costs" I primarily mean costs associated with its being legal for people to sex select. Social costs could arise from many people choosing to sex select, and they could also arise from the mere fact of it being legal to sex select. I will examine four ways in which some people think that social costs could arise.

THREAT TO THE SEX RATIO

It has been claimed that sex selection will lead to a changed sex ratio, with fewer women than men, and that this will lead to inequality for women. It is, however, arguable that if there are fewer women, the women who would exist would be better off because they would be rarer and therefore more valued. ${ }^{17}$ However, it could also be claimed that fewer women than men could be worse for the men since there would be more competition to find partners. (All these points are complicated by nonidentity problems since many of the men would not otherwise have existed.) It is clear that there is much that is speculative here. First, it is far from obvious that sex selection being legal would lead to a disturbed sex ratio. Many people just don't care that much about the sex of their children, and many of those who do will be deterred by the financial costs and the invasiveness of the procedure. Moreover, the evidence cited earlier suggests that the dominant reason for seeking sex selection in prosperous liberal democracies is to have what the people seeking it see as a balanced family, a boy if they have already had two girls perhaps. Overall, the threat to the sex ratio is far from clear. And it is also far from clear what the upshot of a changed sex ratio would be. What is the optimal ratio, whatever that means? To what extent does it depend on variations among the sexes with respect to: attitudes to monogamy, life expectancy, sexual preference, nuclear families, and so on? Until we have answers to these questions, it is even far from obvious that the current sex ratio (roughly 52\% female, $48 \%$ male) is optimal, far from obvious that giving people more choice would not result in an improvement of the sex ratio, and far from obvious that the optimal sex ratio could not be achieved by subsidising the selection of the appropriate sex. Banning it because we don't understand it might be common enough in politics, but that is little to recommend it.

RESOURCE COSTS

It would be hard to make a good case at the moment for the claim that sex selection counts as a health care need, and therefore hard to claim that the state should be subsidising it. But making it legal does not mean there is a commitment to funding it. It could be privately funded. This raises the concern that it will only be available to those who can afford it. But the same is true of many forms of cosmetic surgery and of access to a medical specialist of one's choice. Moreover, it is hard to argue that justice requires equality of access to health care-as opposed to access to a decent minimum level of health care-unless one can argue that justice requires strict economic equality. If there is economic inequality, it will make sense for the better off to buy additional health care insurance, or privately fund exotic elective procedures. ${ }^{18}$ Moreover, even at the same level of economic prosperity and health status, different people are differently risk averse, and may prefer to fund different levels of health care insurance. Nevertheless, if sex selection were to become sufficiently widely used, an argument based on fairness could be made for access to all, in the same way that one could now make a good case for free access to oral contraception.

\section{TOO MUCH CHOICE}

Although I have adopted a framework in which various broad sorts of liberties are regarded as politically fundamental goods, it has been denied that choice is unequivocally a good thing. ${ }^{19}$ This may apply to choices about our children's genes. For example, Schelling says this:

"It may be quite hard for a wife to talk about whether she would not like somebody quite as short as her husband and whether she wished her own musical talent rather than her husband's lack of it to be inherited in her children". ${ }^{20}$

But as Schelling also notes, it is common for couples to discuss-and even difficult to avoid discussing-whether they would like a boy or a girl. By making this choice available, it is difficult to believe that couples are being burdened by having to make one more choice, particularly as it is easy to choose not to think seriously about this choice, and just leave sex to chance.

\section{SLIPPERY SLOPE}

It is sometimes said that sex selection is the first step down the road to genetic enhancement. Many people are opposed to genetic enhancement. Whether there are good grounds for making genetic enhancement illegal if it ever becomes possible is too large an issue to discuss here, but there are two reasons to think that an appeal to genetic enhancement will not provide sufficient grounds for making sex selection illegal.

First, one of the social costs that has often been said to be associated with legalised genetic enhancement (if it ever becomes possible) is that parents will feel pressured to make enhancement choices, because of three factors: (a) a nonenhanced child will be disadvantaged in competing against enhanced children; (b) the parents may feel uncomfortable at the prospect of their child saying: "Why didn't you enhance me?", and (c) there may be significant social pressure on the parents towards making certain sorts of enhancement choices. In my view, it is far from obvious that these factors 
generate a strong case against legalised genetic enhancement, but that aside, the factors are clearly not relevant to sex selection: (a') selecting sex is not enhancing ability; (b') the child won't be able to complain that it wasn't made the opposite sex because had its parents selected the opposite sex it would not exist; (c') boys and girls are approximately equally valued, and the evidence is that most sex selection would be to achieve a balanced family.

Further common objections to legalised genetic enhancement are: (d) the possibility that it will lead to social costs (for example, it may be in the interests of each to be taller than average, so many parents will choose to have taller children than average, so that the average height increases, but because of resource pressure, the human race may need to get shorter, not taller ${ }^{20}$ ); (e) the perception (whether justified or not) that people with traits which are generally selected against are being discriminated against; and (f) the claim that genetic enhancement will lead to reduced genetic diversity, along with various biological and social costs said by some to be associated with reduced diversity. But whether or not these objections provide sufficient grounds to make enhancement illegal, they are not relevant to sex selection: (d') the response to the possibility of social costs has already been covered in our discussion of the disturbed sex ratio and resource costs (note in particular that being a particular sex is not like being tall, a strictly relative advantage); and (e') and ( $\left.f^{\prime}\right)$ : the same as (c'). Thus there is some distance between sex selection and enhancement.

Second, it is far from obvious that, even if we accept that genetic enhancement is objectionable, the increased likelihood (if such there be) that genetic enhancement will come to be accepted if sex selection is legal is sufficient grounds to restrict people's reproductive liberties. Compare freedom of expression. It is standard to regard speech as protected even when it advocates things which are far more morally objectionable than genetic enhancement: compare highly racist and sexist speech. Suppose we accept that such speech brings with it an increased likelihood of seriously objectionable behaviour. In contexts in which people have time to consider the merits of such speech, it is generally regarded that this increased likelihood is not by itself sufficient grounds to restrict the speech. ${ }^{21}$ I suggest that reproductive liberty is sufficiently basic that the analogous claim holds. Given that people will have time to consider the merits of genetic enhancement, the supposed slippery slope from sex selection to genetic enhancement does not itself provide grounds for making sex selection illegal even if genetic enhancement is in some way seriously morally objectionable. Compare also the state making sex selection legal with the state funding university courses in which the arguments for (and against) genetic enhancement are put forward. The former seems no more likely to lead to genetic enhancement coming to be accepted than the latter, but we would regard restrictions of the latter as outrageous.
In summary, the objections based on the threat to the sex ratio, resource costs, too much choice, and the slippery slope do not by themselves provide grounds for restricting people's reproductive liberties.

\section{Conclusion}

If sex selection were widely available, most people considering their reproductive choices would try to address the question of whether they have good reasons to select the sex of their child, and it is almost certain that there would be substantial disagreement. But a different question is what the law on sex selection should be in the face of reasonable disagreement about the merits of sex selection. As in many disputed areas, what is in question is a basic liberty; in this case, the liberty to make one's own reproductive decisions. Some people regard the use others make of reproductive technology (for example contraceptives) to control the number of children they have and at what stage in their lives as frivolous and morally objectionable. Others regard the use of reproductive technology to sex select as frivolous and morally objectionable. And just as there are insufficient grounds for restricting reproductive liberties in the first case, so there are insufficient grounds for restricting reproductive liberties in the second case. The appeals to the liberties of others, harm and social cost are the only kinds of consideration that could justify restricting a basic liberty, but in the context of sex selection these appeals are weak. Making sex selection illegal can only be seen as restriction of one group's basic liberties on the grounds of a set of values held by another group which the first group could reasonably reject, and is inconsistent with appropriate principles for settling reasonable disagreement in pluralistic societies which respect the fact that people are free and equal. Of course, some people oppose such principles, but I have suggested that the grounds for such opposition would apply equally to liberties as basic as those associated with freedom of expression.

Let me finish with an objection to this overall position that is as dismaying as it is frequent. It goes something like this. "You have admitted that the reasonable people take different sides on the morality of sex selection. But why should the people who think it morally acceptable win the legal battle? Haven't you just admitted that some people can reasonably reject this position?" This objection misses a crucial asymmetry. In a pluralistic democratic society built upon the ideals of free and equal citizenry, there is always a presumption in favour of liberty. The burden of proof is always on those who want to restrict the liberty of others. Defenders of the legality of sex selection are not seeking to restrict anyone's liberty, whereas opponents are. So the burden of proof is on the opponents to show that those whose liberties they propose to restrict cannot reasonably reject this restriction. It is never sufficient grounds for one group to restrict the liberty of others that it is clear, as they see it, that the behaviour they are trying to 
restrict is morally objectionable. What must be established is that the behaviour they are trying to restrict itself results in something like significant harm to others or infringement of their basic liberties or significant social costs. In the case of sex selection, I have argued that no such grounds have been established.

\section{Acknowledgments}

Julian Savulescu, Ainsley Newson, Wendy Savage, and an anonymous referee.

David McCarthy, PhD, is Lecturer in the Department of Philosophy, University of Bristol.

\section{References}

1 Fugger E, Black S, Keyvanfar K, Schulman J. Births of normal daughters after microsort sperm separation and intrauterine insemination, in-vitro fertilization, or intracytoplasmic sperm injection. Human Reproduction 1998;13:2367-70.

2 Savulescu J. Sex selection-the case for. Medical fournal of Australia 1999;171:373-5.

3 Thomson J. Abortion. Boston Review 1994/1995;20. http:// bostonreview.mit.edu/BR20.3/thomson.htm

4 Jansen R. Evidence based ethics and the regulation of reproduction. Human Reproduction 1997;12:2068-75.

5 Scanlon $T$. Contractualism and utilitarianism. In: Sen A Williams $\mathrm{B}$, eds. Utilitarianism and beyond. Cambridge: Cambridge University Press, 1982: 103-28.

6 Rawls J. Political liberalism. New York: Columbia University Press, 1993.

7 Scanlon T. Value, desire, and the quality of life. In: Nussbaum M, Sen A, eds. Quality of life. Oxford: Clarendon Press, 1993: $185-200$.
8 Rawls J. Kantian constructivism in moral theory. Fournal of Philosophy 1980;77:515-72.

9 Batzofin J. XY sperm separation for sex selection. Urological Clinics of North America 1987;14:609-18.

10 Lui P, Rose G. Social aspects of over 800 couples coming forward for gender selection of their children. Human Reproduction 1995;10:968-71.

11 Parfit D. Reasons and persons. Oxford: Oxford University Press, 1984.

12 For a discussion of the consequences of this principle to questions about cloning, see McCarthy D. Persons and their copies. fournal of Medical Ethics 1999;25:98-104.

13 Bowen JR, Gibson FL, Leslie GI, Saunders DM. Medical and developmental outcome at 1 year for children conceived by intracytoplasmic sperm injection. Lancet 1998;351:152934 .

14 Dulioust E, Toyama K, Busnel M, Moutier R, Carlier M, Marchaland $\mathrm{C}$, et al. Long-term effects of embryo freezing in mice. Proceedings of the National Academy of Science USA 1995;92. 589-93.

15 Wennerholm UB, Albertsson WK, Bergh C, Hamberger L, Niklasson A, Nilsson L, et al. Postnatal growth and health in children born after cryopreservation as embryos. Lancet 1998; 351:1085-90.

16 Simpson JL, Carson SA. The reproductive option of sex selection. Human Reproduction 1999;14:870-2.

17 Sureau G. Gender selection: a crime against humanity or the exercise of a fundamental right? Human Reproduction 1999;14: $867-8$

18 Gibbard A. Health care and the prospective Pareto principle. Ethics 1984;94:261-82.

19 Frankfurt H. The importance of what we care about. Cambridge: Cambridge University Press, 1968: 156-8: Equality as a moral ideal.

20 Schelling T. Micromotives and macrobehavior. New York: Norton and Company, 1978: 191-210: Choosing our children's genes.

21 Scanlon T. A theory of freedom of expression. Philosophy and Public Affairs 1971-72;1:204-26.

\section{JME website-live and online}

- Fully searchable archive

- Editor's Choice

- Articles collected by topic

- Abstracts

- Cross-journal searching

- Future Content
- Top 10 papers

- eLetters

- Direct access to Medline

- Search/Browse

- Free access to developing countries

- Email table of contents

www.jmedethics.com 